\title{
Adipose Derived Stem Cells Ameliorate Atopic Dermatitis by Down-regulating IL-17 Secretion of Th17 Cells in an Ovalbumin-induced Mouse Model
}

Jingyan Guan ( $\sim$ doctorguanjingyan@outlook.com )

Southern Medical University Nanfang Hospital https://orcid.org/0000-0003-0641-7352

Yibao Li

Southern Medical University Nanfang Hospital

Feng Lu

Southern Medical University Nanfang Hospital

Jingwei Feng

Southern Medical University Nanfang Hospital

\section{Research Article}

Keywords: adipose-derived stem cells, atopic dermatitis, IL-17 signaling pathway, Th17 cells, ovalbumin, mouse model

Posted Date: October 29th, 2021

DOI: https://doi.org/10.21203/rs.3.rs-1014539/v1

License: (9) This work is licensed under a Creative Commons Attribution 4.0 International License. Read Full License 


\section{Abstract}

Background: Mesenchymal stem cells (MSCs) has therapeutic potential for Atopic dermatitis (AD) due to their immunoregulatory effects. However, the underlying mechanisms for therapeutic efficacy of ADSCs on $A D$ is still unclear.

Objectives: We sought to investigate the therapeutic effect and mechanisms of adipose-derived stem cells (ADSCs) on AD using an ovalbumin-induced AD mouse model.

Methods: AD mice were treated with mice-derived ADSCs, cortisone, or PBS. The therapeutic effect was determined via gross examination and additional in vitro assays using skin samples and blood. To further explore the underlying mechanisms, RNA sequencing analyses and co-culture assays were conducted.

Results: ADSCs treatment attenuated the symptoms associated with $A D$, decreased the serum IgE level and mast cells infiltration. Tissue levels of T-cell relevant pro-inflammatory cytokine production, including IL-4R and IL-17A, were suppressed in both ADSCs and cortisone treatment groups. Genomics and bioinformatics analyses demonstrated a significant enrichment of certain of inflammation related pathway in the down regulated genes after the application of ADSCs and cortisone, specifically the IL-17 signaling pathway. Co-culture experiments revealed that ADSCs significantly suppressed the expression of pro-inflammation cytokines IL-17A and RORYT, as well as the proliferation of Th17 cells. Moreover, the expression of PD-L1, TGF- $\beta$, PGE2 was significantly upregulated in the co-cultured ADSCs compare to monocultured ADSCs.

Conclusion: Taken together, our data may demonstrate that ADSCs ameliorate OVA- induced AD in mice by down-regulating IL-17 secretion of Th17 cells.

\section{Background}

Atopic dermatitis (AD) is a chronically recurrent skin disease that is characterized by a disruption of the epidermal barrie, immune dysregulation, and skin flora changes. It affects up to $20 \%$ of children and $10 \%$ of adults worldwide, and it significantly reduces the quality of life for affected individuals[1, 2]. Since many years, it has been considered that the pathogenesis and development of $A D$ are mainly due to the dysregulation of the helper $\mathrm{T}(\mathrm{Th})$ cell immune responses. Therefore, treatments that reduce the helpermediated immune response have been the mainstream therapeutic methods for $A D[3]$. These treatments include non-specific anti-inflammatory and immunosuppressants drugs, such as corticosteroids, calcineurin inhibitors, leukotriene receptor antagonists, and antihistamines. However, these drugs only provide temporary and limited relief of symptoms and are often associated with adverse effects and drug resistance in long-term treatment[4, 5]. In recent years, significant progress has been made toward increasing our understanding of the pathogenesis of AD. Consequently, the development of novel therapies that are safe and efficacious for AD has been intensely pursued. 
Mesenchymal stem cells (MSCs) have been a promising cell-based treatment option for AD due to their unique tissue regenerative capacity and immunomodulatory ability [6, 7]. In comparison to other types of MSCs, adipose-derived stem cells (ADSCs) have several advantages, since adipose tissue can be obtained easily through liposuction with a small incision, and ADSCs can be isolated in large amounts by relatively simple procedure. Although a few studies have demonstrated the use of ADSCs for the attenuation of $A D[8-10]$, the mechanisms involved have yet to be elucidated. Recent studies demonstrated that in addition to classical Th2, other subsets of helper T cells also contribute to the pathogenesis of AD, such as Th1, Th17 and Th22[11, 12]. In this study, we investigated the therapeutic effect of autologous ADSCs on skin lesions in an ovalbumin (OVA)-induced AD mouse model. Furthermore, to verify the mechanistic mode of action, we employed transcriptome profiling and pathway analyses to elucidate the therapeutic mechanism of ADSCs.

\section{Materials And Methods}

\subsection{Isolation and culture of mouse ADSCs}

All animal procedures have been approved by the Institutional Animal Care and Use Committee of Nanfang Hospital, and all operations were performed in accordance with the National Health and Medical Research Council (People's Republic of China) guidelines. All the surgical procedures were performed following the sterility principle. Female balb/c mice ( 6 weeks old, $n=6$ ) were purchased from Nanfang Hospital Animal Center (Guangzhou, China). After shaving, the mice were sacrificed and subcutaneous fat was harvested. About $1.5 \mathrm{~g}$ of fat was acquired from each mouse, and stored in a sterile $50 \mathrm{ml}$ centrifuge tube. After removing red blood cell by washing 3 times with phosphate buffered saline (PBS), the isolated fat was cutting into small pieces. Then $0.2 \%$ type I collagenase (Sigma-Aldrich, St. Louis, Mo.) was used to digest the fat tissue for 45 minutes at $37^{\circ} \mathrm{C}$ with continuous stirring. After digestion, the stromal vascular fraction (SVF) was separated from the adipose tissue by centrifugation $(200 \times \mathrm{g}, 5$ minutes), and resuspended with PBS, then filtered to remove large debris. The SVF suspension underwent an additional round of centrifugation ( $200 \times \mathrm{g}, 5$ minutes) followed by resuspension in complete growth medium comprised of Dulbecco's modified Eagle's Medium (DMEM)-low glucose (GIBCO-BRL, Life Technologies, Gaithersburg, MD), supplemented with $10 \%$ fetal bovine serum (FBS) and $1 \%$ penicillin/streptomycin. The SVF suspension was then plated in T75 cell culture flasks at a density of approximately $5 \times 10^{5}$ cells/flask (P0) and incubated at $37^{\circ} \mathrm{C}$ with $5 \%$ carbon dioxide. Medium was changed at a frequency of once every 3 days and cells were passaged at $90 \%$ confluence. ADSCs that were within the range of passage 3 to passage 5 were used for subcutaneous injection.

\subsection{In vitro differentiation of ADSCs}

To determine the multi-lineage differentiation potential of the ADSCs, they were induced into adipogenic, chondrogenic, and osteogenic lineages using the corresponding growth media, according to a previous 
study[13]. The differentiated fat, cartilage, and bone cels were identified with Oil Red O, Alcian blue, and Alizarin red staining, respectively.

\subsection{Murine Model of AD}

Female balb/c mice ( 6 weeks of age, $\mathrm{n}=24$ ) were maintained at $25^{\circ} \mathrm{C}$ under pathogen-free conditions, with a 12-hour light-dark cycle, and were able to eat and drink freely. The mice were divided into 4 groups ( $n=6$ per group) at random as follows: a. untreated group (normal control, NC); b. OVA-sensitized and PBS treated group (PBS group), c. OVA-sensitized and ADSCs-treated group (ADSCs group), and d. OVAsensitized and cortisone cream-treated group (cortisone group).

A murine model of AD was prepared as described as previous study[14]. Briefly, all mice except for those in the normal control group, were anesthetized with isoflurane and their dorsal skin was shaved, followed by the application of tape stripped six times with 3M tape (Tegaderm, Owens and Minor, Mechanicsville, VA, USA). Subsequently, each mouse was sensitized with OVA $(100 \mu \mathrm{g})$, which was dissolved in $100 \mu \mathrm{l}$ saline and added to a sterile patch. The patch was placed on the dorsal skin for 1 week and then removed. Two weeks later, the procedure described above was repeated for another 1 week. Each mouse was exposed to a total of three 1-week sensitizations, with 2-week intervals. (Figure 1a)

On days 28, 35 and 42 of sensitization and challenge by OVA, mice in the ADSCs group received subcutaneous administration of $1 \mathrm{ml}$ ADSCs suspension with the cell number of $1 \times 10^{6}$. The PBS group mice were subcutaneously injected with $1 \mathrm{ml}$ PBS at the same time points, as a negative control. In the cortisone group, $0.1 \mathrm{~g}$ of cortisone cream (Shufulin, Dinuo, Hunan, China) was daubed to dorsal skin of mice at the same time points, as a positive control. All mice were sacrificed at day 50 , with half of the sensitized dorsal skin fixing in $10 \%$ formalin, and the the other half being stored at $-80^{\circ} \mathrm{C}$ for further dectetion.

\subsection{Measurement of clinical severity}

The severity of dorsal skin lesions was assessed according to six symptoms: erythema/hemorrhage, oozing/crust, erosion/excoriation, swelling/oedema, lichenification and dryness). Scores of 0 to 3 (absent to severe) were given by two independent investigators. The sum of the scores was defined as the clinical severity (scale 0-18).

\subsection{Histological examination}

For histological analyses, skin samples were obtained from the dorsal skins of mice in the four groups at day 50 (24 h after the patch was removed). Skins that soaked in $10 \%$ formalin were prepared into paraffin samples and then cut into $4 \mu \mathrm{m}$ sections for haematoxylin-eosin (H\&E) staining or toluidine blue staining. A microscope (Olympus, Tokyo, Japan) was used to obtain photomicrographs (magnification, $\times 200$ ). Ten 
H\&E staining regions of each group were selected randomly for epidermal thickness analysis using ImageJ software. The infiltrated mast cells were assessed by toluidine blue (TB) staining (10 random regions of each group), and counted by ImageJ software.

\subsection{Measurement of serum Immunoglobulin E (IgE)}

On the day of sacrifice (day 50), the eyeballs of mice were removed to collect whole blood after anesthesia. After clotting at room temperature for 30 minutes, the blood samples were centrifuged at $1000 \times \mathrm{g}$ for 10 minutes at $4^{\circ} \mathrm{C}$. Serum was collected and preserved at $-80^{\circ} \mathrm{C}$ until use. Serum IgE was detected using mouse IgE enzyme-linked immunosorbent assay (ELISA) kit (BioLegend, USA) according to the manufacturer's instructions.

\subsection{RNA Sequencing and Analyses}

The total RNA was extracted from dorsal skin samples from the 4 groups ( $n=3$ per group) using TRIzol (Invitrogen, USA) as shown in the manufacturer's instructions. The quantification of RNAs were implemented using the Quant-IT RiboGreen (Invitrogen, USA), and qualification of RNAs were assessed through the Bioanalyzer 2100 system (Agilent, USA). After the quality inspection, mRNAs were purified, fragmented and converted to first strand complementary DNA (CDNA) with reverse transcriptase. The first cDNA strand was subsequently converted to second CDNA strand, and then end-repair, A-tailing, and adapter ligation were carried out. The AMPure XP system (Beckman Coulter, USA) was used to purify the library fragments and screen out 370-420 bp cDNA fragments. After the libraries were constructed, polymerase chain reaction (PCR) was performed, and the PCR products were purified and qualified using AMPure XP system (Beckman Coulter, USA) and the Agilent Bioanalyzer 2100 system, respectively. Then, a cluster of the index-coded samples were generated using TruSeq PE Cluster Kit v3-cBot-HS (Illumia, USA) on a cBot Cluster Generation System according to the manufacturer's instructions. After that, Novaseq platform (Illumina, USA) was used to sequence the prepared libraries in a 150 bp paired-end to generate raw reads. Through the in-house perl scripts, the raw reads of fastq format were processed into clean reads, and then aligned to the reference genome sequence of Mus musculus (mm10) using the Hisat2 v2.0.5. Finally, the reads numbers of the genes in each group were calculated using FeatureCounts v1.5.0-p3.

For RNA sequencing analyses, we identified the differentially expressed genes (DEGs) between each group using DESeq2 R package (1.20.0) with a significancy threshold for a relative expression fold change $\leq-1$ or $\geq 1(|\log 2 \mathrm{FC}| \geq 1)$ and adjusted $p($ Padj $) \leq 0.05$. The ClusterProfiler R software package was used for the Gene Ontology (GO) enrichment analysis and the Gene and Genome Kyoto Encyclopedia (KEGG) enrichment analysis. The GO terms and reactome pathways with Padj $\leq 0.05$ were considered significantly enriched.

\subsection{Isolation of naiive mouse CD4+ T Cells and differentiation of Th17 cells in vitro}


The spleens and lymph nodes of balb/c female mice (5-10 weeks old) were obtained under aseptic conditions. These two tissues were then placed in PBS supplemented with $1 \%$ penicillin/streptomycin (PBS+), followed by grinding into a suspension using two slides. After filtration through a $120 \mu \mathrm{m}$ pore size nylon mesh, the suspension was replenished using PBS+ and centrifuged at $475 \times \mathrm{g}$ at $4{ }^{\circ} \mathrm{C}$ for $5 \mathrm{~min}$. The lymph node cell pellet was resuspended with $2 \mathrm{ml}$ PBS+. The splenic cell pellet was resuspended with ACK lysis buffer ( $1 \mathrm{ml}$ per spleen) for $1 \mathrm{~min}$ to lyse red blood cells, then $10 \mathrm{ml}$ of PBS+ was added and centrifugated at $475 \times \mathrm{g}$ at $4^{\circ} \mathrm{C}$ for $5 \mathrm{~min}$. The splenic cell pellet was resuspended with $10 \mathrm{ml} \mathrm{PBS+}$ again, and mixed with the lymph node cells suspension. After a final round of centrifugation at $475 \times \mathrm{g}$ at $4^{\circ} \mathrm{C}$ for $5 \mathrm{~min}$, the combined cell pellet was used for CD 4 enrichment.

T-cell enrichment columns (R\&D Systems) and mouse CD4+ T cell isolation kits (Miltenyi Biotech „CA, USA) were used for Naive CD4+ T cells purification through negative selection. For in vitro differentiation, the naive CD4+ T cells were then place in a 6-well plate coated with anti-CD3 and anti-CD28 $(2 \mu \mathrm{g} / \mathrm{mL})$ antibody. The cells was cultured in Roswell Park Memorial Institute (RPMI) -1640 (GIBCO, USA), supplemented with 10\% FBS, 2 mmol / L-glutamine, 1\% penicillin/streptomycin and Th17 polarizing cytokines ( $10 \mathrm{ng} / \mathrm{mL}$ TGF- $\beta$, $20 \mathrm{ng} / \mathrm{mL} \mathrm{IL}-6,10 \mu \mathrm{g} / \mathrm{mL}$ anti-IL-4 antibody, and $10 \mu \mathrm{g} / \mathrm{mL}$ anti-IFN- $\gamma$ antibody). All cytokines and antibodies applied for differentiation of CD4+ T cell were purchased from BD Biosciences.

\subsection{Co-culture of ADSCs and Th17 cells}

The co-culture experiment consisted of three groups: the direct co-culture group (ADSCs + Th17 cells) as an experimental group, and monoculture of Th17 cells and ADSCs respectively as two control groups. For the co-culture group, $1 \times 10^{5}$ ADSCs were placed into a 6-well plate and cultured overnight in $2 \mathrm{ml} \mathrm{DMEM-}$ low glucose, supplemented with 10\% FBS and 1\% penicillin/streptomycin (DMEM-low glucose +), until they became adherent. Then, the medium was changed with $5 \mathrm{ml}$ RPMI-1640 supplemented with 10\% FBS, 2 mmol / L-glutamine and 1\% penicillin/streptomycin (RPMI-1640 +). Th17 cells ( $2 \times 10^{6}$ cells/well) were added to reach a ratio of 20:1 with ADSCs. For the monoculture of Th17 cells, an equal amount of

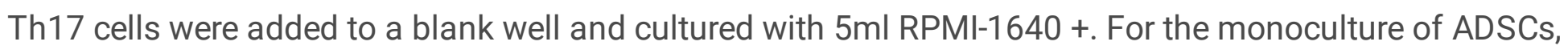
$1 \times 105$ ADSCs were placed into a blank well and cultured with $5 \mathrm{ml}$ DMEM-low glucose + . The ADSCs and Th17 cells of each group were collected after $72 \mathrm{~h}$ of culturing for further experiments.

\subsection{Quantitative Real-Time Polymerase Chain Reaction (qRT-PCR)}

The total RNA was extracted from the skin samples and cell samples with Trizol Reagent (Tiangen Biotech, Beijing, China.), then reverse transcripted into cDNA using a Reverse-Transcription kit (DBI Bioscience, Germany), according to the manufacturer's instructions. FastStart Universal SYBR Green Master (atalogue no. 04913850001; Roche, Switzerland) was used to perform the qRT-PCR. The skin samples were tested for the following genes: interleukin (IL)-13, IL-4, IL-4 receptor (IL-4R), IL-17A, interferon-gamma (IFN- $\gamma$ ) and tumor necrosis factor-alpha (TNF-a). Th17 cell samples were tested for IL17A, IL-17F and RAR-related orphan receptor $Y T$ (RORYT), and ADSCs samples were tested for programed 
death ligand 1 (PD-L1), transforming growth factor- $\beta$ (TGF- $\beta$ ) and prostaglandin E2 (PGE2). The primerprobe sequences of the genes above were shown Supplementary Table 1. Expression levels were determined by the $2^{-\Delta \Delta C t}$ method, and $\beta$-actin was used as an endogenous reference gene.

\subsection{Statistical Analysis}

For RNA sequencing, statistical analysis was implemented by R software (www.R-project.org), and R packages were acquired on Bioconductor (www.bioconductor.org). Regarding the experimental data, they were expressed as mean \pm standard deviation (SD), and analyzed using SPSS Version 21.0 (IBM Corp., USA.). Comparisons was performed using one-way ANOVA for multiple groups, and t tests two groups. $P \leq 0.05$ were considered statistically significant.

\section{Results}

\subsection{The cultured ADSCs exhibited the potential of multi- lineage differentiation}

ADSCs were first subjected to chondrogenic, osteogenic and adipogenic differentiation condition respectively in vitro to test their multi-lineage differentiation potential. As shown in Supplementary Figure 1 , the cells were successfully stained with Alcian blue, Alizarin red and Oil Red 0 respectively, indicating that the ADSCs process capacity of multi-lineage differentiation.

\subsection{Subcutaneous administration of ADSCs ameliorates OVA-induced AD-like skin lesions}

During the OVA-sensitized period, AD-like lesions were successfully induced on the dorsal skin of mice in each group after OVA application. ADSCs $\left(1 \times 10^{6}\right)$, PBS, and cortisone were administrated to OVA-induced $A D$ mice on days 28,35 and 42 for 1 week, and the dorsal skin was assessed to evaluate the therapeutic efficacy of each treatment on day 50. In the PBS group, serious erythema and dryness was observed on the dorsal skin, accompanied by lichenification and excoriation. In comparison with the PBS group, skin lesions were significantly improved in mice that received either ADSCs or cortisone treatment (Figure 1b). Specifically, the clinical severity of the skin lesions in the PBS group (13.11 \pm 0.2606$)$, was significantly lower in groups treated with ADSCs $(9.500 \pm 0.4629, P<0.0001)$ and cortisone $(9.875 \pm 0.4407, P<$ 0.001 ) on day 50 (Figure 1c).

In comparison to the normal control $(16.51 \pm 0.4562 \mu \mathrm{m})$, the epidermis of dorsal skin in PBS-treated mice $(66.80 \pm 1.415 \mu \mathrm{m}, \mathrm{P}<0.0001)$ exhibited remarkable thickening, whereas the epidermal thickness was decreased after administration of ADSCs $(29.97 \pm 1.000 \mu \mathrm{m}, \mathrm{P}<0.0001)$ and cortisone $(36.39 \pm$ $2.727 \mu \mathrm{m}, \mathrm{P}<0.0001)$. Furthermore, epidermal thickness of the ADSC-treated group is slightly lower than the cortisone-treated group ( $\mathrm{P}=0.0081$ ) (Figure $2 \mathrm{a}, \mathrm{c})$. As shown in Figure $2 \mathrm{~b}$ and Figure $2 \mathrm{~d}$, the number of 
infiltrated mast cell was significantly reduced in mice treated with ADSCs $(45.11 \pm 2.232$ cells, $\mathrm{P}<$ $0.0001)$ and cortisone $(43.09 \pm 1.810$ cells, $P<0.0001)$ when compared to the PBS-treated group (66.60 \pm 3.069 cells). Similarly, the level of serum IgE was significantly increased in PBS-treated mice on day 50, whereas treatment with ADSCs and cortisone markedly reduced the level of IgE, which parallels the changes observed in the infiltration of mast cells (Figure 2e).

\subsection{ADSCs decrease the expression of IL-4R and IL-17}

We next determined whether ADSCs could influence the pro-inflammatory cytokine that produced in OVAinduced $A D$ mice. Since the pathogenesis of $A D$ involves the dysfunction of multiple helper $T$ cell types, we performed qRT-PCR to detected the pro-inflammatory cytokines associated with Th1 (TNF-a, IFN- $y$ ), Th2 (IL-13, IL-4, IL-4R), and Th17 (IL-17A) cells. As shown in Figure 3, the expression of all cytokines tested were significantly increased in the PBS group. Compare with the PBS group, the expression of IL4R (Figure 3c) and IL-17A (Figure 3f) were significantly down-regulated after either ADSCs or cortisone treatment. The expression of IFN- $\gamma$ (Figure 3d) and TNF-a (Figure 3e) were slightly decreased in the ADSCand cortisone-treated groups, but the difference was not statistically significant. Whereas, the expression of IL-13 (Figure 3a) and IL-4 (Figure 3b) were slightly increased in the ADSC-treated group, but no statistically significant difference was found.

\subsection{ADSCs normalize the alteration of IL-17 signaling pathway in OVA-induced skin lesions}

To decipher the mechanisms that ADSCs improve the skin lesion, skin lesions from normal control, PBS-, ADSCs-, and cortisone-treated mice were implemented high-throughput RNA sequencing. The result of principal component analysis (PCA) showed that ADSCs group was clearly separated from the normal control, PBS, or cortisone groups (Figure 4a), suggesting that ADSCs regulate a different gene expression program during $A D$ recovery.

By a threshold minimum of $\mid \log 2 \mathrm{FCl} \geq 1$ (Padj $\leq 0.05$ ), a total of $4771 \mathrm{DEGs}$ was identified in the skin specimens of the four groups. All DEGs were organized into a heatmap (Figure $4 \mathrm{~b}$ ). As shown in Figure 4c, there are 2965 DEGs between the PBS and normal control groups, 2641 DEGs between the ADSCs and PBS groups, 933 DEGs between the cortisone and PBS groups, and 1204 DEGs between the ADSCs and cortisone groups.

We then performed GO and KEGG analyses on up-regulated DEGs between the PBS-treated and normal control groups. $\mathrm{GO}$ analysis showed that the top 10 terms associated with biological process (BP), cellular component (CC), and molecular function (MF) were mostly related to epidermis hyperplasia, leukocyte migration, and cytokine related activities (Figure 5a). These results correlate with epidermal thickening and an elevated inflammatory response after OVA sensitization, which is consistent with the histological analyses (Figure 2). In comparison with the normal control group, the result of KEGG analysis 
showed a significant change of the IL-17 signaling pathway in PBS group, illustrating that Th17 cells were remarkably activated after OVA sensitization (Figure $5 b$ ).

Subsequently, GO and KEGG analyses were conducted on the down-regulated DEGs identified between the of ADSCs and PBS groups, as well as the cortisone and PBS groups. The result of GO analysis revealed that the top $10 \mathrm{BP}, \mathrm{CC}$, and MF terms were primarily related to leukocyte activities, bacterium response, and cytokine related activities (Figure $5 \mathrm{c}$ ), which are correlated with alleviation of inflammatory responses after ADSCs and cortisone treatment. As for KEGG analysis, a significant change in the IL-17 signaling pathway was found between the ADSCs and PBS group (ranked ninth) as well as the cortisone and PBS groups (ranked second) (Figure 5d), which suggests that ADSCs and cortisone effectively suppress Th17 cell activation similarly.

\subsection{ADSCs suppress the proliferation and activation of Th17 cell in vitro}

To further identify the mechanism associated with ADSCs-derived inhibition of Th17 cells activation, a direct co-culture of ADSCs and mature Th17 cells was performed. The formation of T-cell receptor (TCR)activated T-cell clusters were observed to evaluate the Th17 cell suppression capability of ADSCs. As shown in Figure $6 \mathrm{a}$, after 72 hours of culturing, less TCR-activated T-cell clusters were formed in the coculture group compared to the monocultured Th17 cells. In addition, the monocultured Th17 cells have proliferated to an amount of $3.774 \pm 0.05802 \times 10^{6}$ in 72 hours, whereas only $0.6310 \pm 0.06552 \times 10^{6}$ Th17 cells were counted in the co-culture group, even less than the initial cell number $\left(2 \times 10^{6}\right)$ (Figure $6 \mathrm{~b}$ ). Correspondingly, the expression levels of IL-17A (Figure 6c), as well as RAR-related orphan receptor $\mathrm{YT}^{\top}$ (RORYT) (Figure 6e), the master transcription factor of Th17 cell differentiation, were reduced under the co-culture condition. The expression of IL-17F was also reduced in the co-culture group, but there was no statistical significance (Figure 6d).

As shown in Figure 7a, there was no obvious morphological difference between the co-cultured and monocultured ADSCs. Whereas, in comparison to monocultured ADSCs, the expression of programed death ligand 1 (PD-L1), transforming growth factor- $\beta$ (TGF- $\beta$ ) and prostaglandin E2 (PGE2) were upregulated in co-cultured ADSCs (Figure 7b to 7d), indicating that these ADSCs derived protein and factors might have roles in the suppression of Th17 cells.

\section{Discussion}

$A D$ is an allergic inflammatory skin disease characterized by (1) disrupted epidermal barrier function[15], (2) dysregulated immune responses, (3) pruritic skin lesions. Stem cells possess immunomodulatory properties and may serve as a promising therapeutic candidate for AD. In the present study, we demonstrate that subcutaneous administration of ADSCs can ameliorate OVA-induced murine AD, probably through down regulating the IL-17 secretion by Th17 Cells. 
The delivery methods of MSCs in AD models mainly include subcutaneous and intravenous injections[16, 17]. Although previous study has reported that ADSCs have homing effects to the injured tissue after intravenous injection[18], other study indicates that this administration route would lead to low viability of stem cells because of pulmonary interception[19]. In addition, some studies demonstrated that local injection of ADSCs have higher viability than intravenous injection[19] [20]. Therefore, we administrated ADSCs directly to the lesion sites utilizing subcutaneous injection. Our results indicated that subcutaneous administration of ADSCs successfully relieved the symptoms, and reduced thickening of the skin.

Mast cells, which are mainly recruited by IgE[21], are considered to play an significant role in the persistence of AD symptoms[22]. Mashiko et al reported that the inhibition of mast cell activities leads to the amelioration of $A D$, whereas increased mast cell activities aggravated $A D$ symptoms[23]. To evaluate whether ADSCs influence the recruitment of mast cells to AD lesion site, we determined the amount of skin mast cells and serum IgE was present in our mouse model. Our data showed that the number of infiltrated mast cells and serum IgE levels were significantly decreased after ADSCs treatment, suggesting an inhibitory effect on mast cell recruitment and local allergic responses.

Although $A D$ is generally considered as a Th2 dominant disease, recent studies reported that other Th cell subsets might be involved in the pathogenesis of $A D$, such as Th1 and Th17[24-26]. Therefore, we performed qRT-PCR to assess whether ADSCs could influence the expression of Th1-, Th2- and Th17defining cytokines. Our data showed that IL-4, IL-4R, IL-13, IFN-y, TNF-a, and IL-17 were significantly increased in lesion sites after OVA induction. In vitro and in vivo studies have shown that the immunosuppressive ability of MSCs depends on preliminary activation by immune cells through the secretion of Th1 associated cytokine IFNy[27, 28] alone, or together with TNFa[29]. The increase of IFN- $\gamma$ and TNF-a in our present study may attribute to the activation of ADSCs. Type 2 inflammation mediated by IL-4 and IL-13 is known to play a central role in AD[30]. Moreover, the activation of IL-4/IL-13/IL-4R axis promotes the differentiation of Th2 cells, which subsequently mediates the pro-allergic adaptive immune response[31, 32]. As a hub for IL-4 and IL-13 acting on downstream inflammatory cells, the IL-4R complex activates multiple signaling pathways that regulate allergic responses, which promote multiple processes in AD immune dysregulation[33]. Interestingly, ADSCs treatment downregulated IL-4R rather than IL-4 and IL-13, indicating that ADSCs may inhibit Th2 inflammation by suppressing the IL-4R expression in various downstream inflammatory cells, but not by decreasing the production of Th2-related cytokines directly. However, the underlying mechanisms remain to be clarified.

Recent studies have indicated that Th17 cells, and the associated cytokine IL-17, are profoundly involved in the pathogenesis of certain skin disorders, such as psoriasis[34, 35]. In addition, IL-17 has been found to participate in allergen-specific immune responses[36, 37]and exhibits increased expression in skin trauma and skin barrier dysfunction-associated diseases[38]. IL-17 has been reported to regulate epidermal cell proliferation conditions and skin thickening[39]. Considering the proinflammatory properties of IL-17, it is interesting to study if, and how Th17 cells are involved in the pathogenesis of AD. Our qRT-PCR results revealed that the expression of IL-17A in skin samples was effectively inhibited in 
ADSC-treated mice. Moreover, RNA-seq analyses identified a remarkable transcriptomic down-regulation in IL-17 signaling pathways in ADSC-treated mice, indicating that the therapeutic effect of ADSCs on AD may be attributed to down-regulating IL-17 secretion by Th17 Cells.

Although the mechanisms behind the immunosuppressive effect of MSCs on Th17 cells have not been fully elucidated, several processes were recently reported, including a dependence on cell-cell contactbased inhibition and the production of soluble factors[40]. In this study, co-culture of ADSCs and Th17 cells was performed to further investigate the immunoregulatory effect of MSCs on Th17 cells. The suppression of IL-17A and IL-17F expression were highly comparable to the T-cell cluster results, suggested that ADSCs exert a stronger immunosuppressive effect on Th17 cells. PD-L1 is an expressed on the cytomembrane of MSCs and plays an important role in the negative regulation of immune responses[41][42, 43]. Our data revealed that PD-L1 accumulated significantly in the co-culture system, indicating that the inhibition of Th17 cells by ADSCs may be partially attributed to the cellular contact of MSCS through PD-L1. Cytokines secreted by MSCs were also reported to have an immunosuppressive effect on immune cell populations. As MSC-derived PGE2 and TGF- $\beta$ have been reported to play an significant role in regulating multiple immune suppressive effects[44][45], they were quantified in our coculture assay. The results revealed that the co-culture group contained higher levels of PGE2 and TGF- $\beta$, in comparison with cells cultured alone, which may explain the immunosuppressive effect of ADSCs on Th17 cells. Collectively, ADSCs exerted an immunosuppressive effect on Th17 cells, which may be attributed to both cell-cell contact inhibition and immunosuppressive cytokines secretion, but further studies are required to clarify the exact mechanisms.

Recent researchs indicated that $A D$ is a highly heterogenous inflammatory skin disease characterized by activation of multiple immune reaction[46-48]. Therapeutic options for AD still remain limited, in part because currently available models do not adequately capture all immune and barrier features of the human AD skin[49-51], being the OVA- induced and NC/Nga mice that best represent it[52]. There remains diversity in immune types between the experimental $A D$ studies and these differences may have resulted from the use of different animal models, model methods and examination methods, etc[53-55]. Although studies haved highlighted a critical role for the Th2 signals in AD[56-58], activation of Th17 and Th22 pathway was also reported to play an important role in the development of $A D[59]$. Especially, recent studies suggested an increased Th17 and Th22 activation in Asian AD and the percentage of Th17 signal level was significantly correlated with the severity of $A D[60-62]$. Therefore, our study may provide some new insights into the understanding and therapeutic approach of Th17 signalling of AD.

This study had some limitations. First, this study applied an OVA-induced AD mice model. Use of reliable animal models (i.e. xenograft or bioengineered skin-humanized mouse) that can capture more AD features would be desirable. Second, recent study demonstrated that the different MSC lines had different immumodulatory properties efficacy[63], therefore, a comparision of therapeutic effect between different MSC lines on the AD mice skin would deepen our understanding regarding the therapeutic mechanisms of AD based on MSCs. Third, the therapeutic effects of stem cell are mainly attributed to their tissue regenerative capacity and immunomodulatory ability, but this study only investigated the 
immunomodulatory ability of ADSCs on AD. Further studies to clarify the tissue regenerative capacity of $A D S C$ s on $A D$ are required.

\section{Conclusion}

MSC-based therapy is a promising and potent approach for human allergic diseases, especially for AD. In this study, subcutaneous injection of ADSCs ameliorated AD by down-regulating IL-17 secretion of Th17 cells in ovalbumin-induced mouse model. Our results demonstrated that ADSCs might become a promising therapeutic medication for AD. Moreover, our findings might further expand the knowledge about the mechanisms of MSC-based therapy for AD.

\section{Abbreviations}

MSCs: mesenchymal stem cells

AD: Atopic dermatitis

ADSCs: adipose-derived stem cells

OVA: ovalbumin

Th: helper T

PBS: phosphate buffered saline

SVF: stromal vascular fraction

DMEM: Dulbecco's modified Eagle's Medium

FBS: fetal bovine serum

NC: normal control

H\&E: haematoxylin-eosin

TB: toluidine blue

IgE: Immunoglobulin E

ELISA: enzyme-linked immunosorbent assay

cDNA: complementary DNA

PCR: polymerase chain reaction

DEGs: differentially expressed genes 
Padj: adjusted $p$

GO: Gene Ontology

KEGG: Gene and Genome Kyoto Encyclopedia

PBS+: PBS supplemented with $1 \%$ penicillin/streptomycin

RPMI: Roswell Park Memorial Institute

DMEM-low glucose +: DMEM-low glucose supplemented with 10\% FBS and 1\% penicillin/streptomycin

RPMI-1640 +: RPMI-1640 supplemented with 10\% FBS, 2 mmol / L-glutamine and 1\% penicillin/streptomycin

qRT-PCR: quantitative real-time polymerase chain reaction

IL: interleukin

IL-4R: IL-4 receptor

IFN-y: interferon-gamma

TNF-a: tumor necrosis factor-alpha

RORYT: RAR-related orphan receptor ${ }^{T}$

PD-L1: programed death ligand 1

TGF- $\beta$ : transforming growth factor- $\beta$

PGE2: prostaglandin E2

SD: standard deviation

PCA: principal component analysis

BP: biological process

CC: cellular component

MF: molecular function

TCR: T-cell receptor

\section{Declarations}




\section{Ethics approval and consent to participate}

All animal procedures have been approved by the Institutional Animal Care and Use Committee of Nanfang Hospital.

\section{Consent for publication}

Not applicable.

\section{Availability of data and materials}

The datasets used and/or analysed during the current study are available from the corresponding author on reasonable request.

\section{Competing interests}

The authors declare that they have no competing interests.

\section{Funding}

This study was supported by the National Nature Science Foundation of China $(81601702,81671931$, $81701920,81801933,82102350,82002058)$, Natural Science Foundation of Guangdong Province of China (2017A030313900).

\section{Authors' contributions}

JG carried out the experiments, data analyses and manuscript writing. YL participated in the in vivo experiments. FL and JF designed the study and revised the manuscript. All authors read and approved the final manuscript.

\section{Acknowledgements}

Not applicable.

\section{References}

1. Deckers IA, McLean S, Linssen S, Mommers M, van Schayck CP, Sheikh A. Investigating international time trends in the incidence and prevalence of atopic eczema 1990-2010: a systematic review of 
epidemiological studies. PLOS ONE. 2012;7(7):e39803. doi:10.1371/journal.pone.0039803.

2. Asher MI, Montefort S, Bjorksten B, Lai CK, Strachan DP, Weiland SK et al. Worldwide time trends in the prevalence of symptoms of asthma, allergic rhinoconjunctivitis, and eczema in childhood: ISAAC Phases One and Three repeat multicountry cross-sectional surveys. LANCET. 2006;368(9537):73343. doi:10.1016/S0140-6736(06)69283-0.

3. Kennedy K, Heimall J, Spergel JM. Advances in atopic dermatitis in 2017. J Allergy Clin Immunol. 2018;142(6):1740-7. doi:10.1016/j.jaci.2018.10.012.

4. Saeki H, Nakahara T, Tanaka A, Kabashima K, Sugaya M, Murota H et al. Clinical Practice Guidelines for the Management of Atopic Dermatitis 2016. J DERMATOL. 2016;43(10):1117-45. doi:10.1111/1346-8138.13392.

5. Silverberg NB, Duran-McKinster C. Special Considerations for Therapy of Pediatric Atopic Dermatitis. DERMATOL CLIN. 2017;35(3):351-63. doi:10.1016/j.det.2017.02.008.

6. Nauta AJ, Fibbe WE. Immunomodulatory properties of mesenchymal stromal cells. BLOOD. 2007;110(10):3499-506. doi:10.1182/blood-2007-02-069716.

7. Uccelli A, Moretta L, Pistoia V. Mesenchymal stem cells in health and disease. NAT REV IMMUNOL. 2008;8(9):726-36. doi:10.1038/nri2395.

8. Park A, Park H, Yoon J, Kang D, Kang M, Park Y et al. Priming with Toll-like receptor 3 agonist or interferon-gamma enhances the therapeutic effects of human mesenchymal stem cells in a murine model of atopic dermatitis. STEM CELL RES THER. 2019;10(1). doi:10.1186/s13287-019-1164-6.

9. Shin TH, Lee BC, Choi SW, Shin JH, Kang I, Lee JY et al. Human adipose tissue-derived mesenchymal stem cells alleviate atopic dermatitis via regulation of B lymphocyte maturation. Oncotarget. 2017;8(1):512-22. doi:10.18632/oncotarget.13473.

10. Park H, Son H, Choi M, Son Y, Kim S, Hong H et al. Adipose-derived stem cells attenuate atopic dermatitis-like skin lesions in NC/Nga mice. EXP DERMATOL. 2019;28(3):300-7. doi:10.1111/exd.13895.

11. Guttman-Yassky E, Nograles KE, Krueger JG. Contrasting pathogenesis of atopic dermatitis and psoriasis-part II: immune cell subsets and therapeutic concepts. J Allergy Clin Immunol. 2011;127(6):1420-32. doi:10.1016/j.jaci.2011.01.054.

12. Suarez-Farinas M, Dhingra N, Gittler J, Shemer A, Cardinale I, de Guzman SC et al. Intrinsic atopic dermatitis shows similar TH2 and higher TH17 immune activation compared with extrinsic atopic dermatitis. J Allergy Clin Immunol. 2013;132(2):361-70. doi:10.1016/j.jaci.2013.04.046.

13. Eterno V, Zambelli A, Pavesi L, Villani L, Zanini V, Petrolo G et al. Adipose-derived Mesenchymal Stem Cells (ASCs) may favour breast cancer recurrence via HGF/c-Met signaling. Oncotarget. 2014;5(3):613-33. doi:10.18632/oncotarget.1359.

14. Spergel JM, Mizoguchi E, Brewer JP, Martin TR, Bhan AK, Geha RS. Epicutaneous sensitization with protein antigen induces localized allergic dermatitis and hyperresponsiveness to methacholine after single exposure to aerosolized antigen in mice. J CLIN INVEST. 1998;101(8):1614-22. doi:10.1172/JCl1647. 
15. Palmer CN, Irvine AD, Terron-Kwiatkowski A, Zhao Y, Liao H, Lee SP et al. Common loss-of-function variants of the epidermal barrier protein filaggrin are a major predisposing factor for atopic dermatitis. NAT GENET. 2006;38(4):441-6. doi:10.1038/ng1767.

16. Kim HS, Lee JH, Roh KH, Jun HJ, Kang KS, Kim TY. Clinical Trial of Human Umbilical Cord BloodDerived Stem Cells for the Treatment of Moderate-to-Severe Atopic Dermatitis: Phase I/Ila Studies. STEM CELLS. 2017;35(1):248-55. doi:10.1002/stem.2401.

17. Kim M, Lee SH, Kim Y, Kwon Y, Park Y, Lee HK et al. Human Adipose Tissue-Derived Mesenchymal Stem Cells Attenuate Atopic Dermatitis by Regulating the Expression of MIP-2, miR-122a-SOCS1 Axis, and Th1/Th2 Responses. FRONT PHARMACOL. 2018;9:1175. doi:10.3389/fphar.2018.01175.

18. Li X, Wang Q, Ding L, Wang Y, Zhao Z, Mao N et al. Intercellular adhesion molecule-1 enhances the therapeutic effects of MSCs in a dextran sulfate sodium-induced colitis models by promoting MSCs homing to murine colons and spleens. STEM CELL RES THER. 2019;10(1):267. doi:10.1186/s13287019-1384-9.

19. Vilalta M, Dégano IR, Bagó J, Gould D, Santos M, García-Arranz M et al. Biodistribution, Long-term Survival, and Safety of Human Adipose Tissue-derived Mesenchymal Stem Cells Transplanted in Nude Mice by High Sensitivity Non-invasive Bioluminescence Imaging. STEM CELLS DEV. 2008;17(5):993-1004. doi:10.1089/scd.2007.0201.

20. Kim H, Yun J, Shin T, Lee S, Lee B, Yu K et al. Human Umbilical Cord Blood Mesenchymal Stem CellDerived PGE2 and TGF- $\beta 1$ Alleviate Atopic Dermatitis by Reducing Mast Cell Degranulation. STEM CELLS. 2015;33(4):1254-66. doi:10.1002/stem.1913.

21. Stone KD, Prussin C, Metcalfe DD. IgE, mast cells, basophils, and eosinophils. J ALLERGY CLIN IMMUN. 2010;125(2, Supplement 2):S73-80. doi:https://doi.org/10.1016/j.jaci.2009.11.017.

22. Mashiko S, Bouguermouh S, Rubio M, Baba N, Bissonnette R, Sarfati M. Human mast cells are major IL-22 producers in patients with psoriasis and atopic dermatitis. J ALLERGY CLIN IMMUN. 2015;136(2):351-9. doi:10.1016/j.jaci.2015.01.033.

23. Ando T, Xiao W, Gao P, Namiranian S, Matsumoto K, Tomimori Y et al. Critical Role for Mast Cell Stat5 Activity in Skin Inflammation. CELL REP. 2014;6(2):366-76. doi:10.1016/j.celrep.2013.12.029.

24. Guttman-Yassky E, Nograles KE, Krueger JG. Contrasting pathogenesis of atopic dermatitis and psoriasis-Part II: Immune cell subsets and therapeutic concepts. J ALLERGY CLIN IMMUN. 2011;127(6):1420-32. doi:10.1016/j.jaci.2011.01.054.

25. Tian X, Liu B, Chen L, Xie Y, Liang J, Yang Y et al. RNA-Seq Identifies Marked Th17 Cell Activation and Altered CFTR Expression in Different Atopic Dermatitis Subtypes in Chinese Han Populations. FRONT IMMUNOL. 2021;12:628512. doi:10.3389/fimmu.2021.628512.

26. M S, N D, J G, A S, I C, de Guzman Strong C et al. Intrinsic atopic dermatitis shows similar TH2 and higher TH17 immune activation compared with extrinsic atopic dermatitis. The Journal of allergy and clinical immunology. 2013;132(2):361-70. doi:10.1016/j.jaci.2013.04.046.

27. Krampera M, Cosmi L, Angeli R, Pasini A, Liotta F, Andreini A et al. Role for interferon-gamma in the immunomodulatory activity of human bone marrow mesenchymal stem cells. Stem cells (Dayton, 
Ohio). 2006;24(2):386-98. doi:10.1634/stemcells.2005-0008.

28. Polchert D, Sobinsky J, Douglas GW, Kidd M, Moadsiri A, Reina E et al. IFN-y activation of mesenchymal stem cells for treatment and prevention of graft versus host disease. EUR J IMMUNOL. 2008;38(6):1745-55. doi:10.1002/eji.200738129.

29. Ren G, Zhang L, Zhao X, Xu G, Zhang Y, Roberts Al et al. Mesenchymal Stem Cell-Mediated Immunosuppression Occurs via Concerted Action of Chemokines and Nitric Oxide. CELL STEM CELL. 2008;2(2):141-50. doi:10.1016/j.stem.2007.11.014.

30. Gandhi NA, Pirozzi G, Graham NMH. Commonality of the IL-4/IL-13 pathway in atopic diseases. EXPERT REV CLIN IMMU. 2017

31. Chiaramonte MG, Mentink-Kane M, Jacobson BA, Cheever AW, Whitters MJ, Goad MEP et al. Regulation and Function of the Interleukin 13 Receptor a 2 During a T Helper Cell Type 2-dominant Immune Response. J EXP MED. 2003;197(6):687-701. doi:10.1084/jem.20020903.

32. Howard TD, Koppelman GH, Xu J, Zheng SL, Postma DS, Meyers DA et al. Gene-Gene Interaction in Asthma: IL4RA and IL13 in a Dutch Population with Asthma. The American Journal of Human Genetics. 2002;70(1):230-6. doi:10.1086/338242.

33. Harb H, Chatila TA. Mechanisms of Dupilumab. Clinical \& Experimental Allergy. 2019;50(1):5-14. doi:10.1111/cea.13491.

34. Albanesi C, Scarponi C, Cavani A, Federici M, Nasorri F, Girolomoni G. Interleukin-17 is produced by both Th1 and Th2 lymphocytes, and modulates interferon-gamma- and interleukin-4-induced activation of human keratinocytes. J INVEST DERMATOL. 2000;115(1):81-7. doi:10.1046/j.15231747.2000.00041.x.

35. Zheng Y, Danilenko DM, Valdez P, Kasman I, Eastham-Anderson J, Wu J et al. Interleukin-22, a T(H)17 cytokine, mediates IL-23-induced dermal inflammation and acanthosis. NATURE. 2007;445(7128):648-51. doi:10.1038/nature05505.

36. Nakae S, Komiyama Y, Nambu A, Sudo K, Iwase M, Homma I et al. Antigen-specific T cell sensitization is impaired in IL-17-deficient mice, causing suppression of allergic cellular and humoral responses. IMMUNITY. 2002;17(3):375-87. doi:10.1016/s1074-7613(02)00391-6.

37. Kolls JK. Oxidative stress in sepsis: a redox redux. J CLIN INVEST. 2006;116(4):860-3. doi:10.1172/JCl28111.

38. Sugaya M. The Role of Th17-Related Cytokines in Atopic Dermatitis. INT J MOL SCI. 2020;21(4):1314. doi:10.3390/ijms21041314.

39. L W, X C, J Z, B M, JA Z, JS K et al. A novel IL-17 signaling pathway controlling keratinocyte proliferation and tumorigenesis via the TRAF4-ERK5 axis. The Journal of experimental medicine. 2015;212(10):1571-87. doi:10.1084/jem.20150204.

40. Terraza-Aguirre C, Campos-Mora M, Elizondo-Vega R, Contreras-Lopez RA, Luz-Crawford P, Jorgensen $C$ et al. Mechanisms behind the Immunoregulatory Dialogue between Mesenchymal Stem Cells and Th17 Cells. CELLS-BASEL. 2020;9(7). doi:10.3390/cells9071660. 
41. Keir ME, Butte MJ, Freeman GJ, Sharpe AH. PD-1 and Its Ligands in Tolerance and Immunity. ANNU REV IMMUNOL. 2008;26(1):677-704. doi:10.1146/annurev.immunol.26.021607.090331.

42. Kim J, Park M, Kim Y, Ryu K, Lee KH, Cho K et al. Tonsil-derived mesenchymal stem cells (T-MSCs) prevent Th17-mediated autoimmune response via regulation of the programmed death1/programmed death ligand-1 (PD-1/PD-L1) pathway. J TISSUE ENG REGEN M. 2018;12(2):e102233. doi:https://doi.org/10.1002/term.2423.

43. Duffy MM, Pindjakova J, Hanley SA, McCarthy C, Weidhofer GA, Sweeney EM et al. Mesenchymal stem cell inhibition of T-helper 17 cell- differentiation is triggered by cell-cell contact and mediated by prostaglandin E2 via the EP4 receptor. EUR J IMMUNOL. 2011;41(10):2840-51. doi:10.1002/eji.201141499.

44. Harris SG, Padilla J, Koumas L, Ray D, Phipps RP. Prostaglandins as modulators of immunity. TRENDS IMMUNOL. 2002;23(3):144-50. doi:10.1016/s1471-4906(01)02154-8.

45. Svobodova E, Krulova M, Zajicova A, Pokorna K, Prochazkova J, Trosan P et al. The role of mouse mesenchymal stem cells in differentiation of naive T-cells into anti-inflammatory regulatory T-cell or proinflammatory helper T-cell 17 population. STEM CELLS DEV. 2012;21(6):901-10. doi:10.1089/scd.2011.0157.

46. Brunner PM, Leung D, Guttman-Yassky E. Immunologic, microbial, and epithelial interactions in atopic dermatitis. Ann Allergy Asthma Immunol. 2018;120(1):34-41. doi:10.1016/j.anai.2017.09.055.

47. Agache I, Akdis C, Jutel M, Virchow JC. Untangling asthma phenotypes and endotypes. ALLERGY. 2012;67(7):835-46. doi:10.1111/j.1398-9995.2012.02832.x.

48. Czarnowicki T, He H, Krueger JG, Guttman-Yassky E. Atopic dermatitis endotypes and implications for targeted therapeutics. J Allergy Clin Immunol. 2019;143(1):1-11. doi:10.1016/j.jaci.2018.10.032.

49. Martel BC, Lovato P, Baumer W, Olivry T. Translational Animal Models of Atopic Dermatitis for Preclinical Studies. Yale J Biol Med. 2017;90(3):389-402

50. Guerrero-Aspizua S, Carretero M, Conti CJ, Del RM. The importance of immunity in the development of reliable animal models for psoriasis and atopic dermatitis. IMMUNOL CELL BIOL. 2020;98(8):626-38. doi:10.1111/imcb.12365.

51. Nakajima S, Nomura T, Common J, Kabashima K. Insights into atopic dermatitis gained from genetically defined mouse models. J Allergy Clin Immunol. 2019;143(1):13-25. doi:10.1016/j.jaci.2018.11.014.

52. Ewald DA, Noda S, Oliva M, Litman T, Nakajima S, Li X et al. Major differences between human atopic dermatitis and murine models, as determined by using global transcriptomic profiling. J Allergy Clin Immunol. 2017;139(2):562-71. doi:10.1016/j.jaci.2016.08.029.

53. Ewald DA, Noda S, Oliva M, Litman T, Nakajima S, Li X et al. Major differences between human atopic dermatitis and murine models, as determined by using global transcriptomic profiling. J Allergy Clin Immunol. 2017;139(2):562-71. doi:10.1016/j.jaci.2016.08.029. 
54. Eyerich K, Brown SJ, Perez WB, Tanaka RJ, Bissonette R, Dhar S et al. Human and computational models of atopic dermatitis: A review and perspectives by an expert panel of the International Eczema Council. J Allergy Clin Immunol. 2019;143(1):36-45. doi:10.1016/j.jaci.2018.10.033.

55. Chan LS, Robinson N, Xu L. Expression of interleukin-4 in the epidermis of transgenic mice results in a pruritic inflammatory skin disease: an experimental animal model to study atopic dermatitis. $J$ INVEST DERMATOL. 2001;117(4):977-83. doi:10.1046/j.0022-202x.2001.01484.x.

56. Thaci D, Simpson EL, Beck LA, Bieber T, Blauvelt A, Papp K et al. Efficacy and safety of dupilumab in adults with moderate-to-severe atopic dermatitis inadequately controlled by topical treatments: a randomised, placebo-controlled, dose-ranging phase 2b trial. LANCET. 2016;387(10013):40-52. doi:10.1016/S0140-6736(15)00388-8.

57. Francuzik W, Alexiou A, Worm M. Safety of dupilumab in patients with atopic dermatitis: expert opinion. EXPERT OPIN DRUG SAF. 2021;20(9):997-1004. doi:10.1080/14740338.2021.1939673.

58. Beck LA, Thaci D, Hamilton JD, Graham NM, Bieber T, Rocklin R et al. Dupilumab treatment in adults with moderate-to-severe atopic dermatitis. N Engl J Med. 2014;371(2):130-9. doi:10.1056/NEJMoa1314768.

59. Suarez-Farinas M, Dhingra N, Gittler J, Shemer A, Cardinale I, de Guzman SC et al. Intrinsic atopic dermatitis shows similar TH2 and higher TH17 immune activation compared with extrinsic atopic dermatitis. J Allergy Clin Immunol. 2013;132(2):361-70. doi:10.1016/j.jaci.2013.04.046.

60. Cesare AD, Meglio PD, Nestle FO. A role for Th17 cells in the immunopathogenesis of atopic dermatitis? J INVEST DERMATOL. 2008;128(11):2569-71. doi:10.1038/jid.2008.283.

61. Koga C, Kabashima K, Shiraishi N, Kobayashi M, Tokura Y. Possible pathogenic role of Th17 cells for atopic dermatitis. J INVEST DERMATOL. 2008;128(11):2625-30. doi:10.1038/jid.2008.111.

62. Noda S, Suarez-Farinas M, Ungar B, Kim SJ, de Guzman SC, Xu H et al. The Asian atopic dermatitis phenotype combines features of atopic dermatitis and psoriasis with increased TH17 polarization. J Allergy Clin Immunol. 2015;136(5):1254-64. doi:10.1016/j.jaci.2015.08.015.

63. Yoo HS, Yi T, Cho YK, Kim WC, Song SU, Jeon MS. Mesenchymal Stem Cell Lines Isolated by Different Isolation Methods Show Variations in the Regulation of Graft-versus-host Disease. IMMUNE NETW. 2013;13(4):133-40. doi:10.4110/in.2013.13.4.133.

\section{Figures}


Balb/c mice

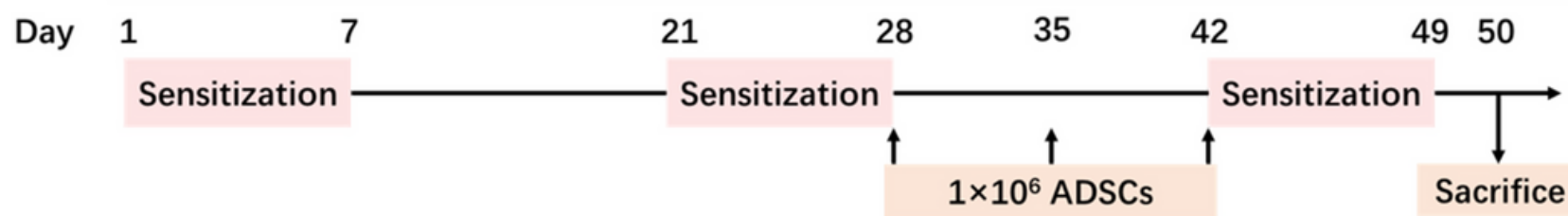

b

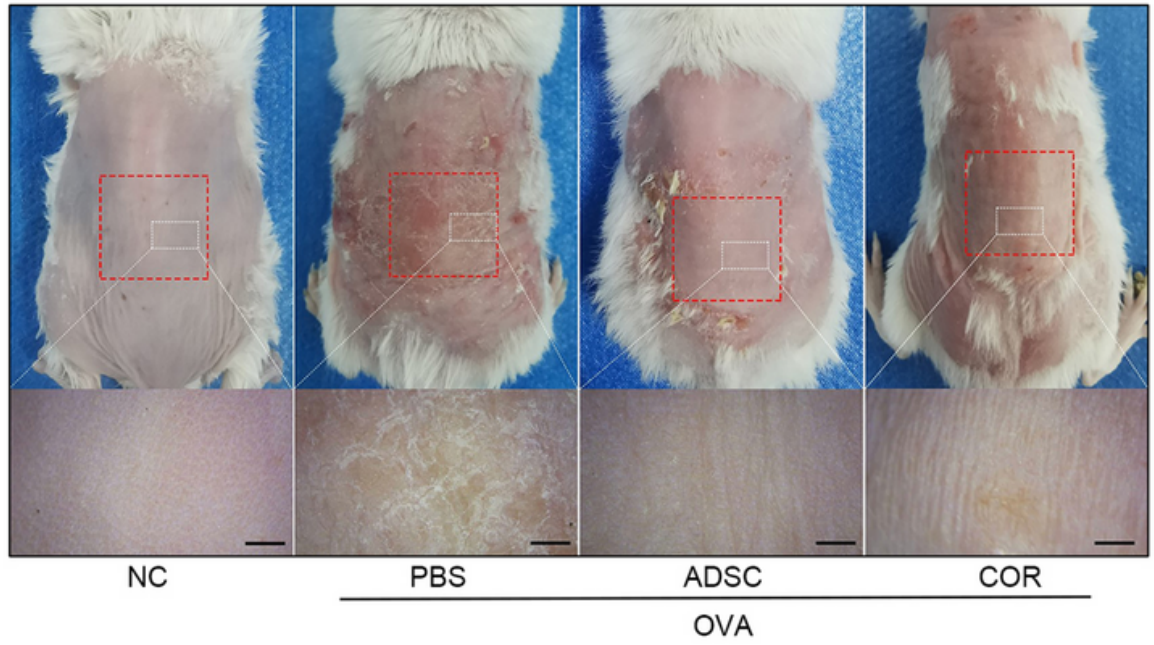

C

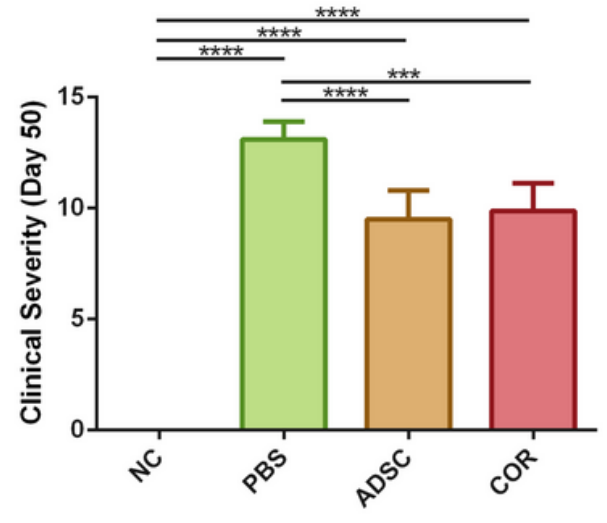

Figure 1

ADSCs alleviated the symptoms of OVA-induced AD in a murine model. (a) Overall scheme of OVA sensitization and ADSCs application in the AD mouse model. OVA was applied to the dorsal skin of BALB/c mice for three 1-week with an interval time of 2 weeks. ADSCs were subcutaneously injected on days 28, 35 and 42 and mice were sacrifice on day 50. (b) Representative photographs and enlarge images of dorsal skin lesions of the AD mice model on day 50. Red dotted boxes represent the areas covered by gauzes. White dotted boxes represent the areas of enlarge images. Scale bar $=1 \mathrm{~mm}$. (c) Clinical severity of the skin lesions assessed before sacrificed on day $50 . n=6$ per group; $\star \star \star, ~ P<0.001$; $\star \star \star \star, ~ P<0.0001$. OVA, ovalbumin; NC, normal control; PBS, phosphate buffer saline; ADSC, adiposederived stem cell; COR, cortisone. 
a
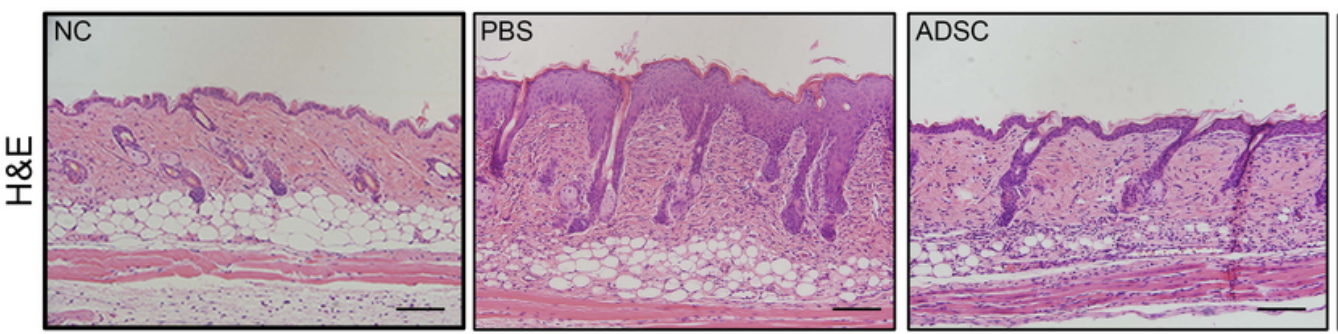

b

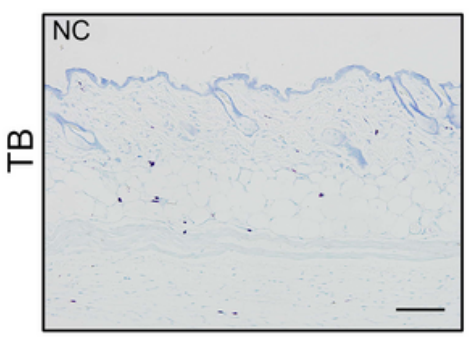

C

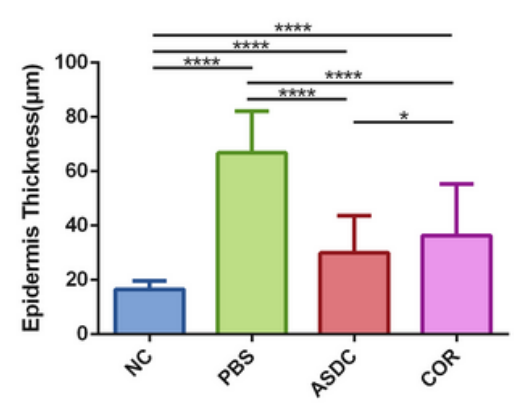

d

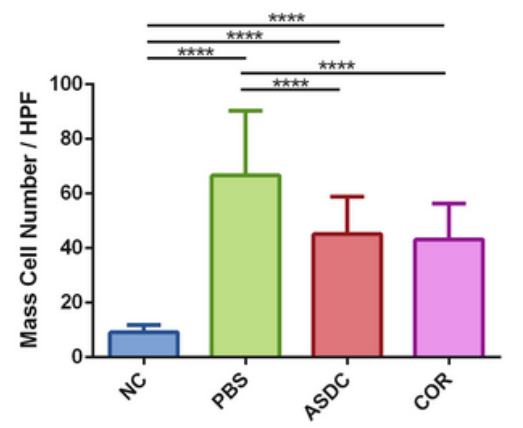

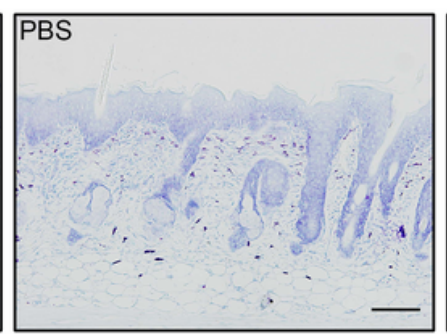
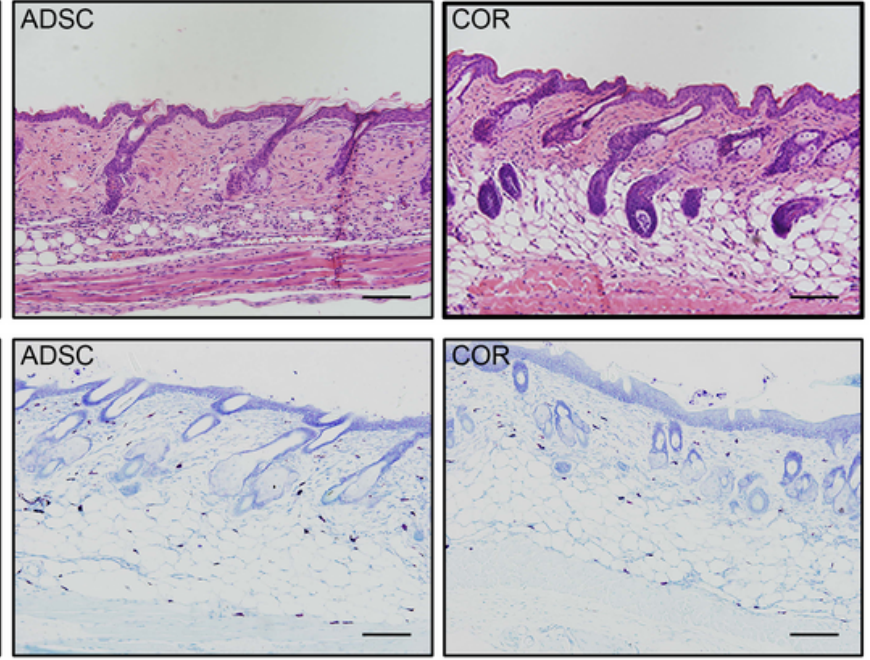

e

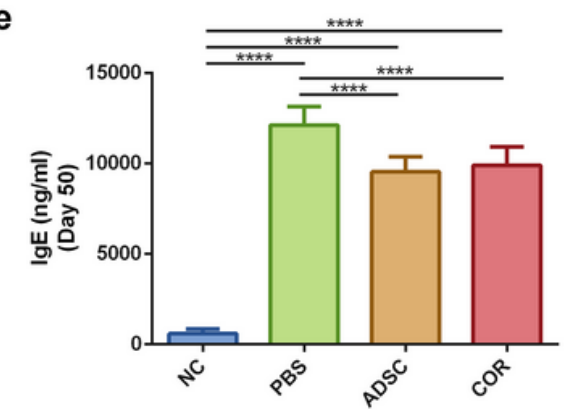

Figure 2

ADSCs improved histopathologic features of lesion sites and serum IgE in mice with OVA-induced AD. (a) Representative H\&E staining photomicrographs of the four groups. (b) Representative TB staining photomicrographs of the four groups. (c) Epidermal thickness measured from the H\&E staining photomicrographs through Image $\mathrm{J}$ software ( $\mathrm{n}=10$ per group). (d) The number of mast cells measured from the TB staining photomicrographs through Image $J$ software $(n=10$ per group). (e) Serum IgE level on day 50 ( $n=6$ per group). ${ }^{\star}, p<0.05 ;{ }^{\star \star \star \star}, \mathrm{p}<0.0001$. Scale bar $=100 \mu \mathrm{m}$. NC, normal control; PBS, phosphate buffer saline; ADSC, adipose-derived stem cell; COR, cortisone. 
a

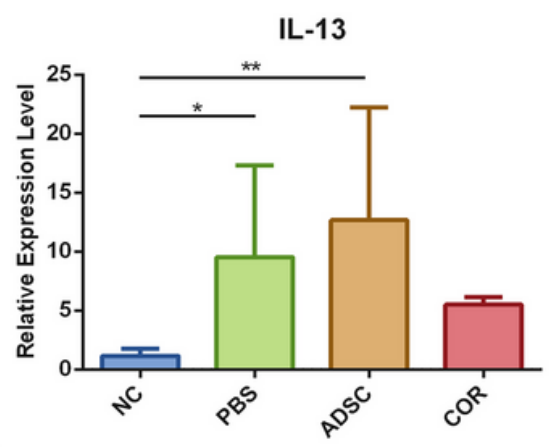

b

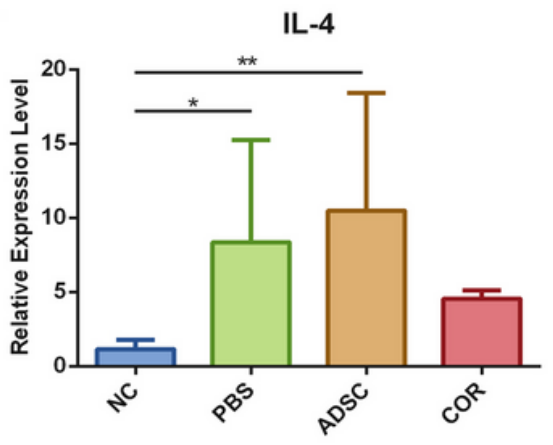

C

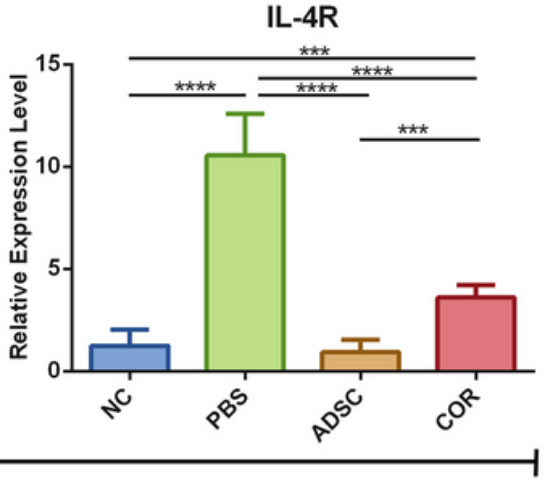

d

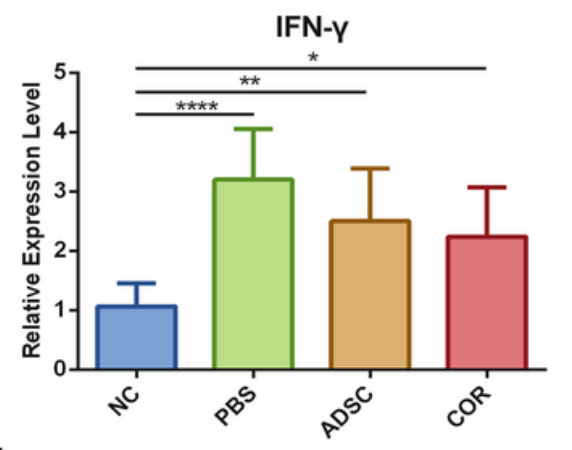

e

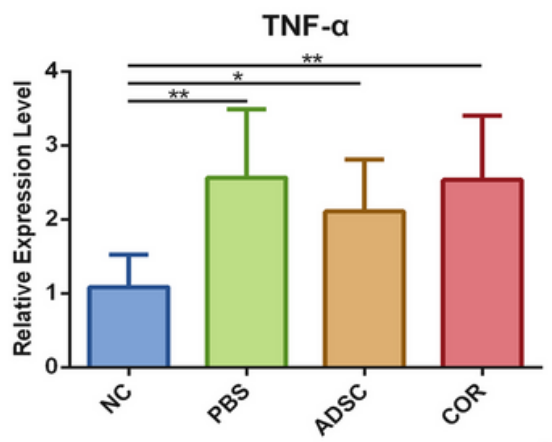

Th1

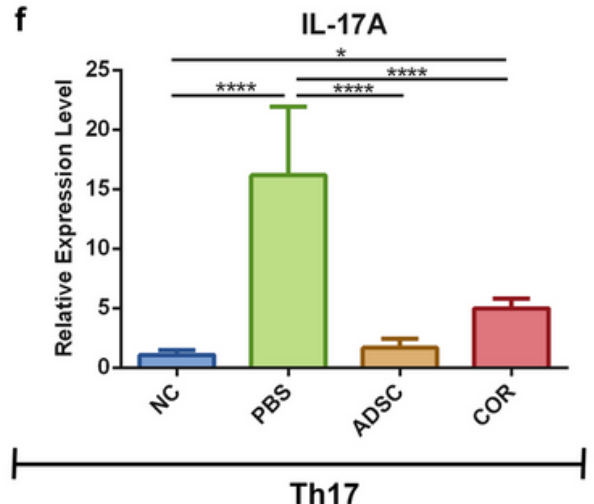

Figure 3

Administration of significantly decreased the expression of IL-4R and IL-17A. The relative expression levels of (a) IL-13, (b) IL-4, (c) IL-4R, (d) IFN-y, (e) TNF- $a$ and (f) IL-17A in the skin lesions measured by

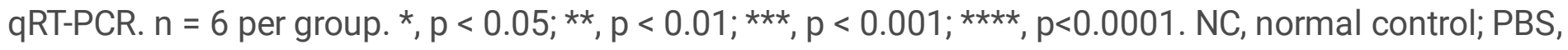
phosphate buffer saline; ADSC, adipose-derived stem cell; COR, cortisone; IL, interleukin; IL-4R, IL-4 receptor; IFN- $\gamma$, interferon-gamma; TNF-a, tumor necrosis factor-alpha. 
a

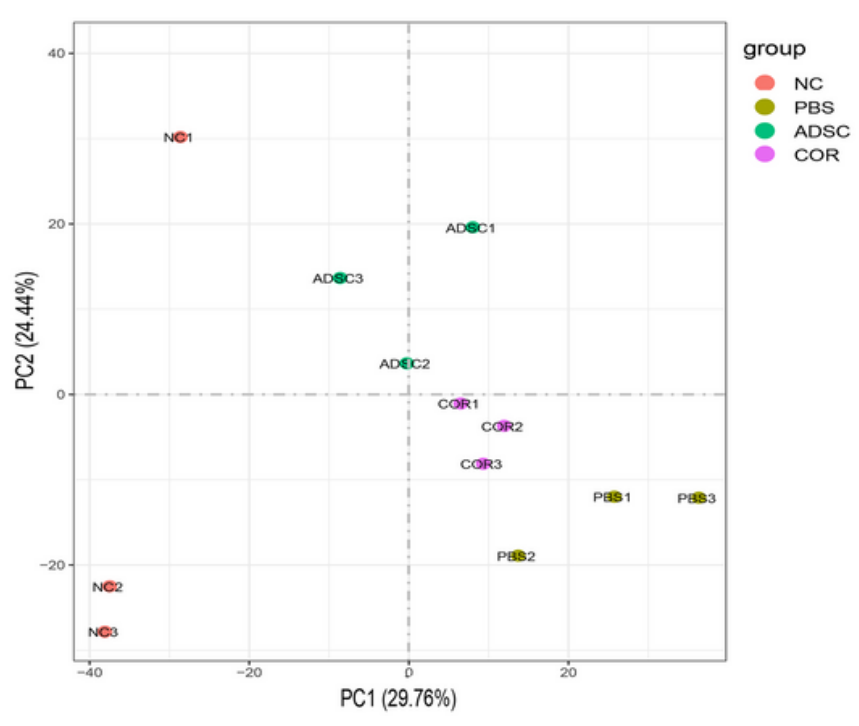

c

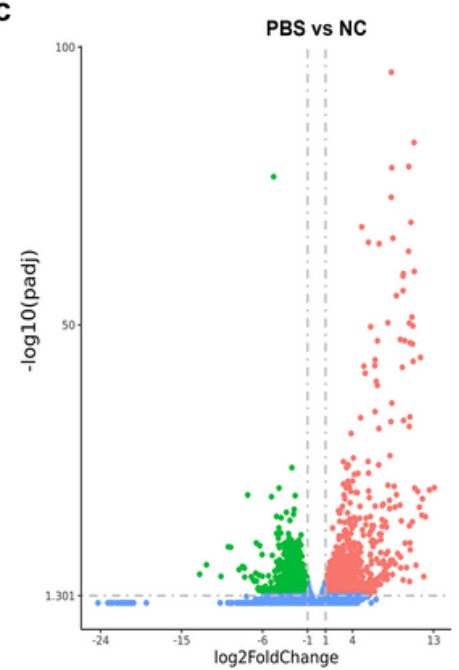

b
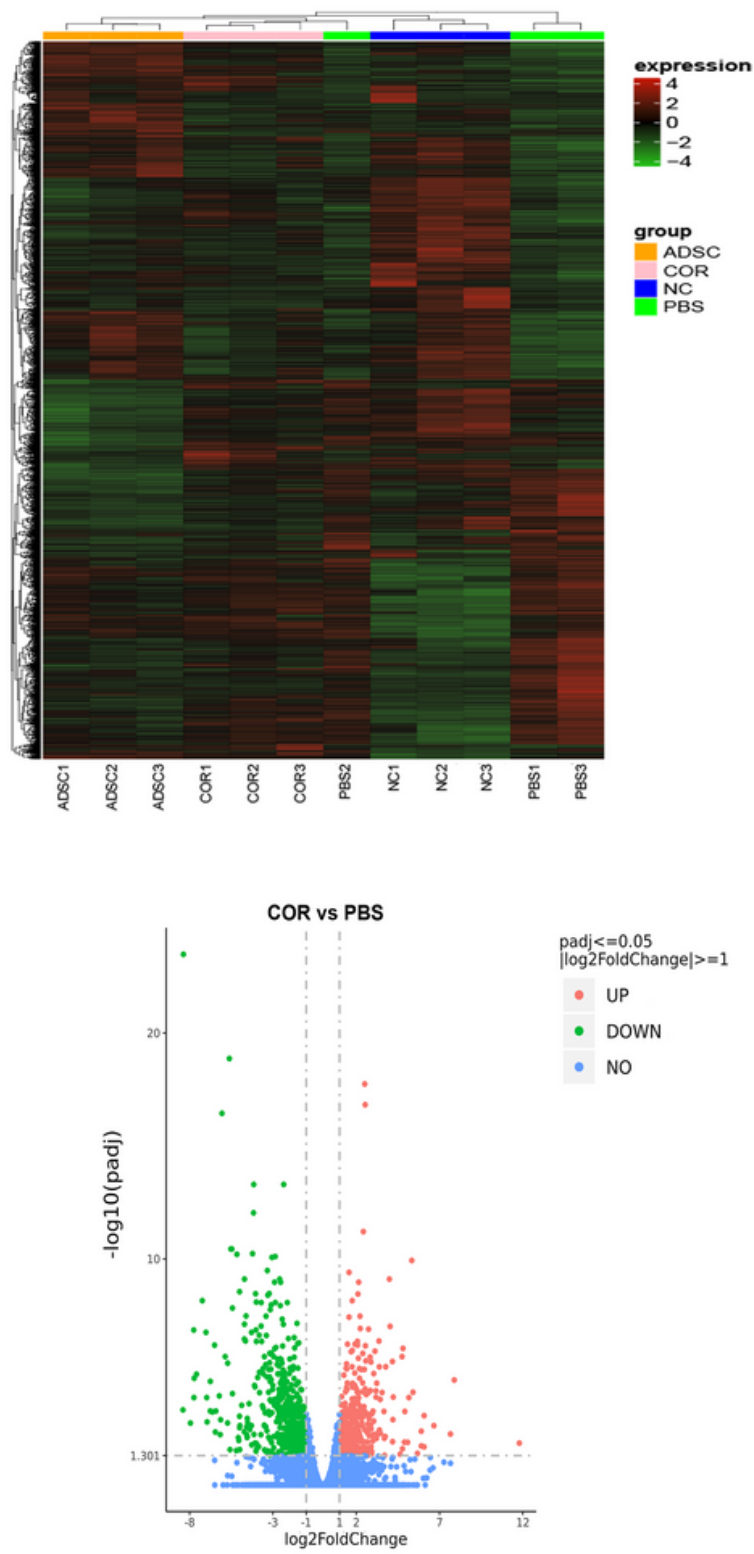

padj $<=0.05$ | log2FoldChange|>=1

- UP

- DOWN

- NO

\section{Figure 4}

RNA sequencing analyses between the NC, PBS, ADSC and COR groups. (a) The PCA of the skin lesions in these four groups. (b) Sample cluster analysis based on the expression pattern of DEGs in these four groups. (c) Volcano plot of DEGs between the PBS and NC groups, the ADSC and PBS groups, and the COR and PBS groups identified by differential expression analysis. $n=3$ per group. NC, normal control; PBS, phosphate buffer saline; ADSC, adipose-derived stem cell; COR, cortisone; PCA, principal component analysis. 


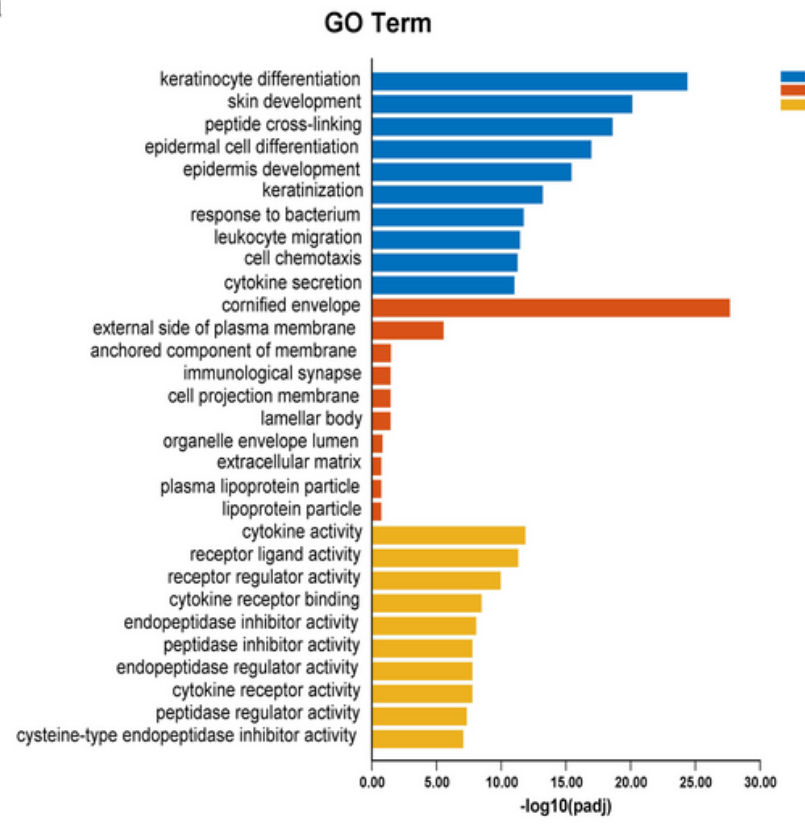

C

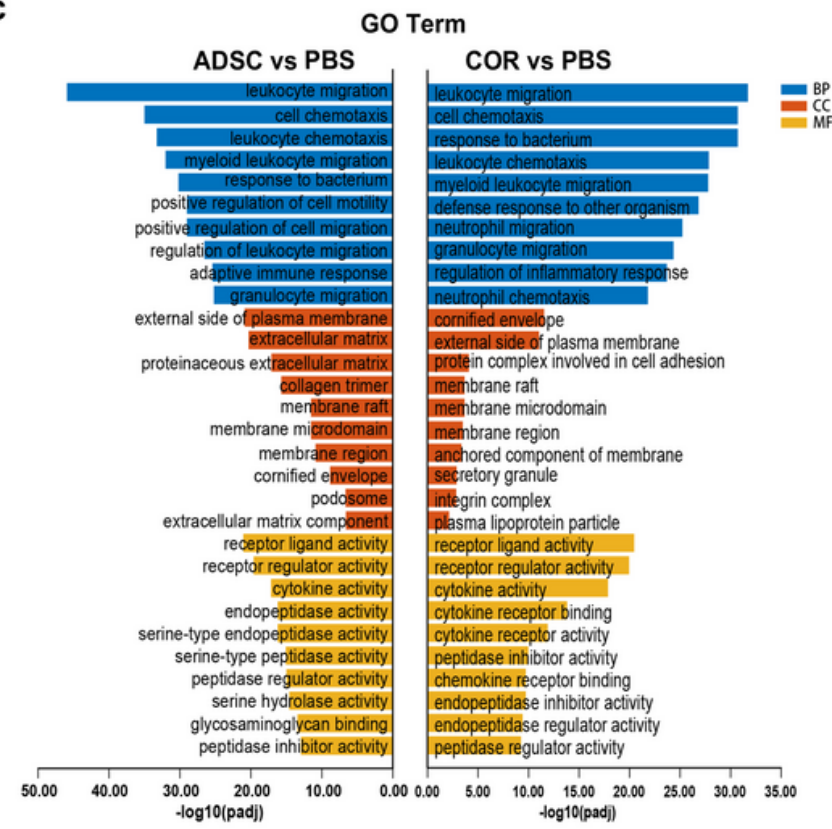

b

KEGG Pathway

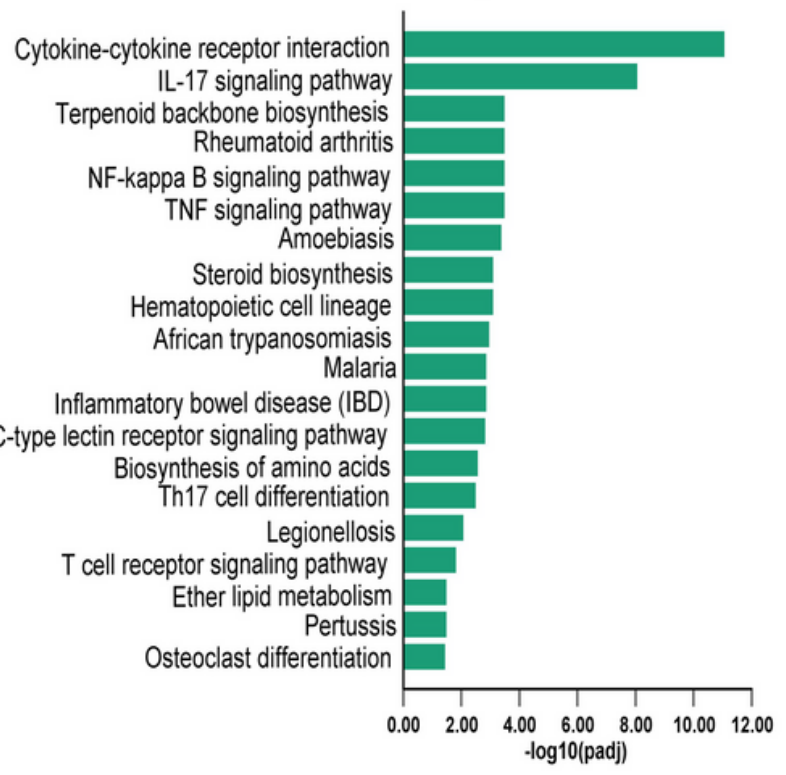

d

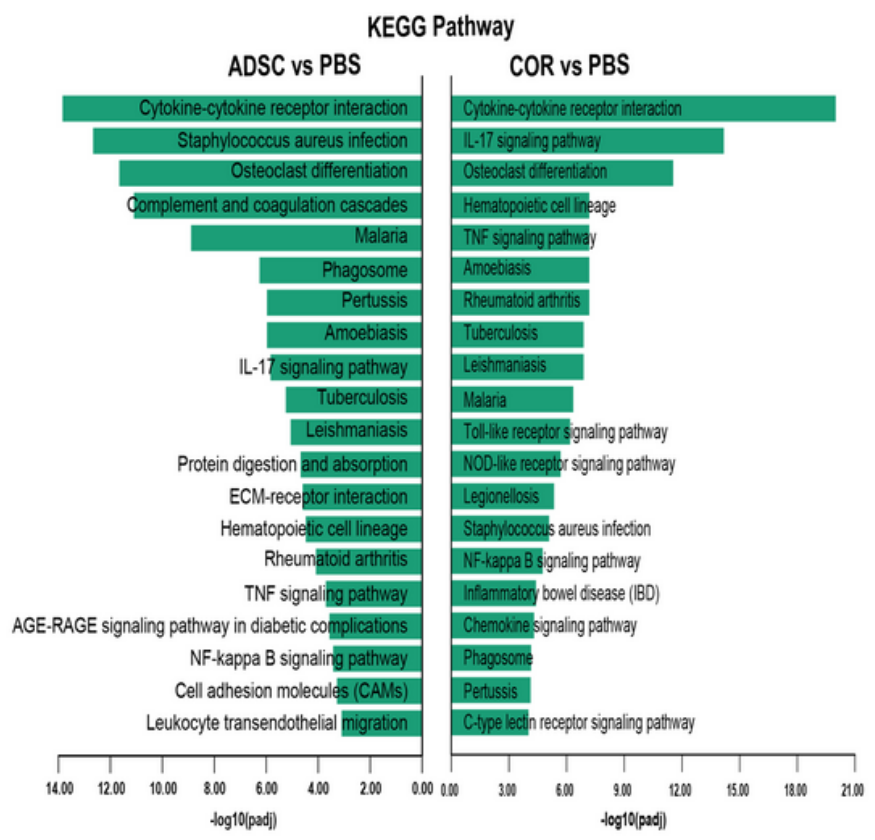

\section{Figure 5}

Administration of ADSCs significantly reversed the abnormal IL-17 signaling pathway in AD skin lesions. (a) Top 10 GO terms about BP, CC and MF of the up-regulated DEGs of PBS vs NC group. (b) Top 20 enriched KEGG pathways of the up-regulated DEGs of PBS vs NC group. (c) Top $10 \mathrm{GO}$ terms about BP, $C C$ and MF of the down-regulated DEGs of ADSC vs PBS and COR vs PBS groups. (d) Top 20 enriched KEGG pathways of the down-regulated DEGs of ADSC vs PBS and COR vs PBS groups. $n=3$ per group. NC, normal control; PBS, phosphate buffer saline; ADSC, adipose-derived stem cell; COR, cortisone; BP, biological process; CC, cellular component; MF, molecular function. 


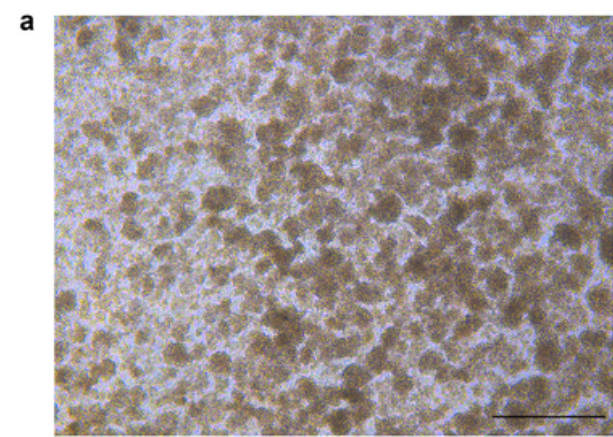

Moculture

c

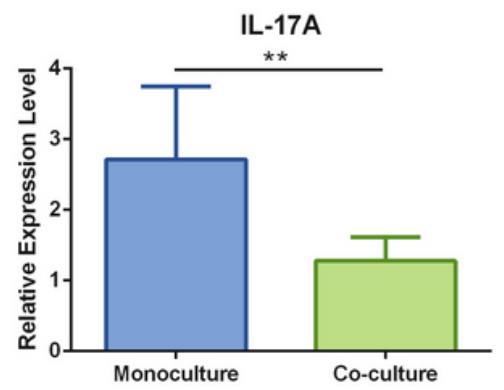

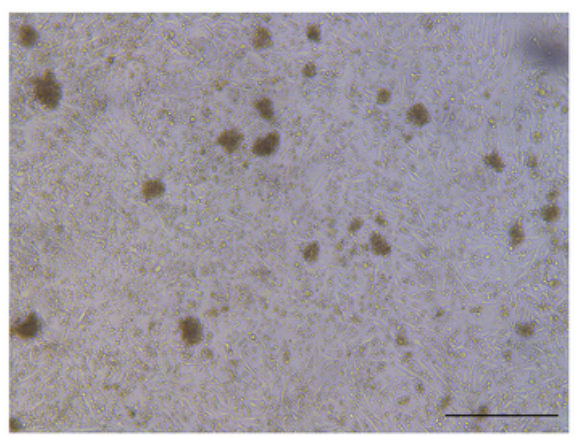

Co-culture

d

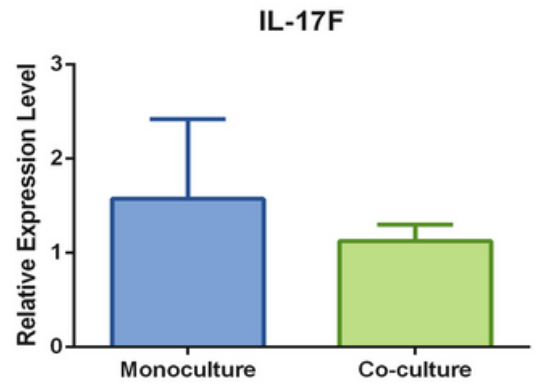

b

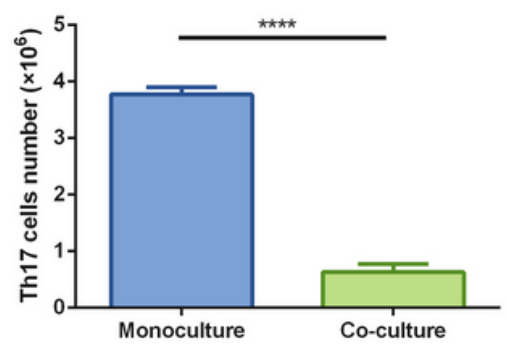

e

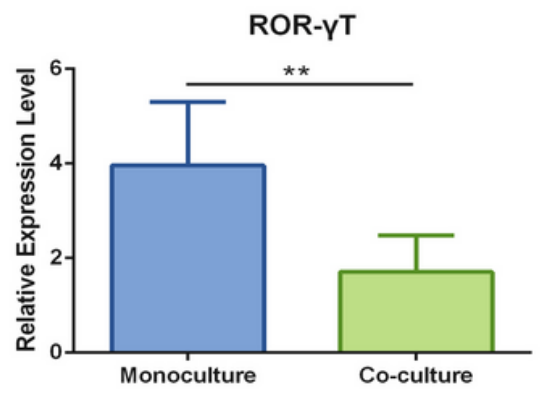

Figure 6

ADSCs suppressed the proliferation and activation of Th17 cell in vitro. (a) Representative photomicrographs of the monocultured (left) and co-cultured (right) Th17 cells at the time point of 72h. Scale bar $=500 \mu \mathrm{m}$. (b) Cell count of the monocultured and co-cultured Th17 cells at the time point of 72h. And the relative expression level of (c) IL-17A, (d) IL-17F and (e) RORYT measured by qRT-PCR. $\mathrm{n}=5$ per group. *, $p<0.05 ; * \star, p<0.01 ; * \star \star \star, p<0.0001$. ADSCs, Adipose-derived stem cells; Interleukin, IL; RORYT, RAR-related orphan receptor $Y$ T.

\section{Figure 7}

The expression of PD-L1, TGF- $\beta$ and PGE2 were increased in the co-cultured ADSCs. (a) Representative photomicrographs of the monocultured (left) and co-cultured (right) ADSCs at the time point of 72h. Scale bar $=200 \mu \mathrm{m}$. And the relative expression level of (b) PD-L1, (c) TGF- $\beta$ and (d) PGE2 measured by quantitative real-time polymerase chain reaction (qRT-PCR). $n=5$ per group. $*, p<0.05$. ADSCs, Adiposederived stem cells; PD-L1, programed death ligand 1 ; TGF- $\beta$, transforming growth factor- $\beta$; PGE2, prostaglandin E2.

\section{Supplementary Files}

This is a list of supplementary files associated with this preprint. Click to download.

- Supplementaryfigure1.tif 
- supplementarytable1.docx

Page 26/26 